\title{
Experiment on the Influence Factors of Steam Distillation Rate of Crude Oil in Porous Media
}

\author{
Guoqing Tian ${ }^{1}$, Wenzhuang Xu${ }^{1}$, Hangjuan Huang ${ }^{1}$, Zhiti Xie ${ }^{1}$, Junzhou Huo ${ }^{1}$ and Yongsheng $\mathrm{Li}^{2}$ \\ ${ }^{1}$ The sixth gas production plant, Changqing Oilfield Branch, Petro China, Shanxi, China \\ ${ }^{2}$ Chongqing Guotian Technology Co. Ltd. Chongqing, China
}

\begin{abstract}
To explore the influence of complexity of reservoir properties in porous media and the diversity of operating conditions on the steam distillation rate of crude oil in the process of heavy oil exploitation with steam injection, steam distillation simulation devices are used to study steam distillation rate of crude oil in porous media. Then steam distillation ratio is obtained under the condition of different core permeability, oil saturation, steam temperatures, system pressure, steam injection rates and steam distillation rates with different viscosities of crude oil. The results show that the steam distillation rate of crude oil in porous media depends mainly on the nature of the crude oil itself, for temperature and pressure are the key factors compared with the pore structure, the initial oil saturation and steam injection rate. The experimental results help estimate the amount of crude oil and the required steam in the reservoir in the steam drive process, aiming to facilitate the optimization design and operation of steam drive.
\end{abstract}

Keywords. Steam distillation rate, steam drive, influencing factors, porous media, experiment, heavy oil.

\section{Introduction}

The distillation of crude oil in porous media is one of the major mechanisms in viscous oil recovery driven by steam, which is determined by distillation characteristics of crude oil at high temperature [1,2]. Willman, et al, believed that the recovery of steam distillation mechanism was up to $5 \% \sim 19 \%$ when the temperature reached $270{ }^{\circ} \mathrm{C}$ [3]. Johnson pointed that the recovery range of steam distillation was $54.7-94.0 \%$ by volume of crude oil [4]. Farouq Ali held the view that the total steam distillation accounted for $5 \%$ to $10 \%$ of the steam drive recovery [5]. K.C. Hong estimated that for the reservoir with the crude oil viscosity of $5 \mathrm{mPa} \cdot \mathrm{s}$, the contribution of steam distillation to the steam drive recovery was $18 \%$ [6]. Several reports on site test items of steam drive indicate that the remaining oil saturation of the steam drive region was less than $10 \%$, the contribution of the steam distillation to the recovery was estimated at around $10 \%[7-11]$.

Although the steam distillation mechanism is considered as an important mechanism of steam drive recovery, there are few researches on the intensified distillation in the porous medium reservoirs, letting alone the factors affecting the steam distillation rates. The intensified distillation theory and technology in the chemical process could facilitate the development of oil filed development to a degree. Obviously, different from the distillation device in the plant, it is necessary to establish the reservoir distillation theory for the porous medium reservoir based on the chemical distillation theory, thus forming the new oil recovery technology.

\section{Experimental device}

The simulated experimental device of steam distillation is as shown in Figure 1. The main body of the device is a distillation chamber, outside the distillation chamber is low carbon steel and the middle section is corrosion-resistant stainless steel. The length of the distillation chamber is $600 \mathrm{~mm}$ and the diameter which is $178 \mathrm{~mm}$ can be placed vertically and horizontally. The steam distillation chamber is divided into upper and lower parts. As for the upper part of the distillation chamber, there are baffle plate, separator and baffles; the baffle plate system is used to prevent the upward drive of oil and only the condensate can go through the buffer system, and then the separator system. In the lower part, there are no baffle plate, separator and baffles, which are used for core sand and oil filling. The steam is injected from the lower part of the distillation chamber and then the steam distillation is conducted by the core sand and 
crude oil. The products pass through the baffle plate and baffle system and then through the valve, condenser and backpressure regulator to enter the gas-liquid separation device. To get a uniform temperature distribution, there are 10 electric boiling plates on the external part of the distillation chamber surrounded by the thermal insulation materials, and the temperature can be controlled automatically.

The flow rate of the steam generator ranges from $1 \mathrm{ml} / \mathrm{min} \sim 180 \mathrm{ml} / \mathrm{min}$ and can be controlled and adjusted automatically. The middle part between the steam generator and steam chamber is wrapped by the electric heater and insulating jacket to prevent heat loss. The steam temperature of the pipeline $3 \sim 5^{\circ} \mathrm{C}$ higher than that of the steam chamber is to prevent condensation of steam in the pipeline.

The fluid collection system consists of a condenser, back pressure regulators, gas-liquid separator, dry ice room and wet type gas meter.

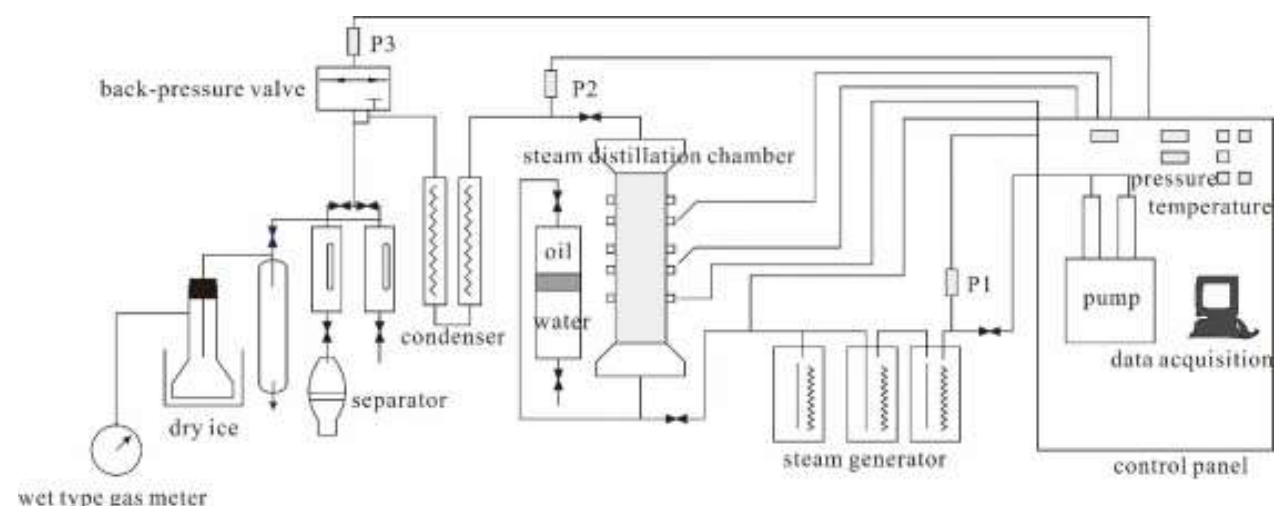

Fig. 1. Simulated device of steam injection distillation.

\section{Experimental procedures}

Put the oil sample in the steam distillation chamber or fill in the porous medium first and then load the crude oil. To carry out the latter method, it is necessary to determine the porosity and permeability, and the other procedures are consistent.

Clean the steam distillation chamber with cyclohexane (or xylene), inject acetone (or ethanol), and then dry it with hot nitrogen to determine the porosity and permeability.

Fill in the upper part of the distillation chamber with nitrogen after being vacuumized and pump the bottom of chamber to saturate oil and water. Then close the top and bottom valves of the chamber.

Heat the distillation chamber, pipelines and the steam generator according to the pre-set temperature, and supply water to the steam generator at a constant rate. Control the outlet pressure by the back-pressure regulator (the back pressure is slightly lower than the saturation pressure- $0.02 \mathrm{MPa}$ under the experiment temperature). Open the top valve of the distillation chamber to release the steam and open the bottom valve, then the steam goes into the steam chamber, so the experiment of steam distillation begins.

Collect the produced fluids (oil and water) regularly and terminate the experiment when the content of oil is less than $0.4 \%$. Calculate the amount of residue by the mass balance.

\section{Experimental results}

\subsection{The influence of permeability on the steam distillation of crude oil}

The crude oil is reserved in the porous media and it is heterogeneous in the longitudinal direction and horizontal plane. As the pore structure and connectivity of the rock may pose certain influence on the steam distillation rate of the crude oil [12], the influence of permeability on the steam distillation rate of crude oil is respectively measured at three levels at four different temperature points, and the experimental results are as shown in Table 1.

Table 1 indicates that under the constant experimental temperature and pressure, the steam distillation rate of the same oil slightly increases with the rise of permeability with no significant difference found. The maximum difference between the three measured permeability is $2.0 \%$ at the same temperature. The reason is that on the one hand, the steam distillation of steam leads to the significant decline in the interfacial tension of oil - water and oil - rock, so that some of the semi-enclosed oil is eroded, increasing the chance of drive, as shown in Figure 2; but on the other hand, the core used in the experiment is artificial. Although there are differences in permeability and porosity, the connectivity is good and there is almost no stagnant pore 


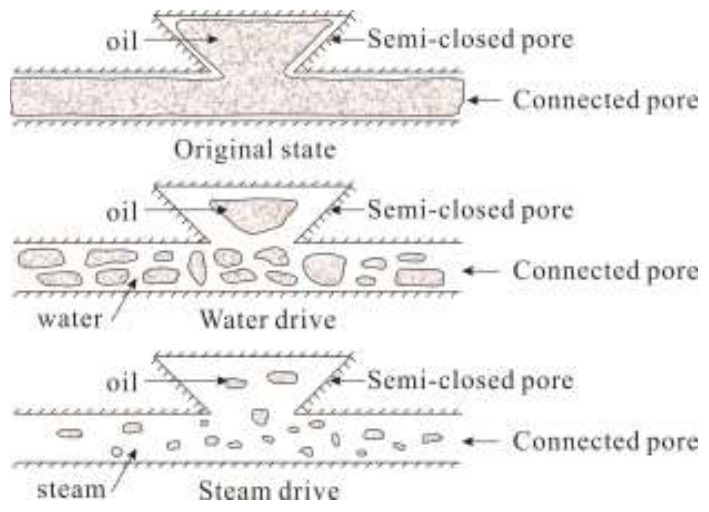

Fig. 2. The erosion effect of steam drive in water-wet system.

Table 1. The steam distillation rate of crude oil under different permeability.

\begin{tabular}{|c|c|c|c|c|c|}
\hline NO & $\begin{array}{c}\text { Permeability } \\
{\mu \mathrm{m}^{2}}^{2}\end{array}$ & $\begin{array}{c}\text { Temperature } \\
{ }^{\circ} \mathrm{C}\end{array}$ & $\begin{array}{c}\text { Pressure } \\
\text { MPa }\end{array}$ & $\begin{array}{l}\mathrm{Vw} / \mathrm{Voi} \\
\mathrm{cm}^{3} / \mathbf{c m}^{3}\end{array}$ & $\begin{array}{c}\text { Distill Rate } \\
\%\end{array}$ \\
\hline 1 & 0.783 & \multirow{3}{*}{150} & \multirow{3}{*}{0.442} & 1.712 & 11.1 \\
\hline 2 & 1.56 & & & 1.688 & 12.2 \\
\hline 3 & 3.15 & & & 1.715 & 12.4 \\
\hline 4 & 0.783 & \multirow{3}{*}{200} & \multirow{3}{*}{1.53} & 2.012 & 13.6 \\
\hline 5 & 1.56 & & & 1.948 & 14.4 \\
\hline 6 & 3.15 & & & 2.021 & 15.3 \\
\hline 7 & 0.783 & \multirow{3}{*}{250} & \multirow{3}{*}{3.95} & 3.318 & 18.7 \\
\hline 8 & 1.56 & & & 3.292 & 19.6 \\
\hline 9 & 3.15 & & & 2.324 & 20.7 \\
\hline 10 & 0.783 & \multirow{3}{*}{300} & \multirow{3}{*}{8.55} & 3.423 & 23.8 \\
\hline 11 & 1.56 & & & 3.398 & 24.5 \\
\hline 12 & 3.15 & & & 3.421 & 25.6 \\
\hline
\end{tabular}

\subsection{The influence of oil saturation on the steam distillation rate of crude oil}

The fluids in the reservoir typically include three phases-oil, gas and water. For the heavy oil reservoirs, there are only two phases-oil and water, because there is no gas. In the steam injection production of heavy oil, the injected steam should be used to heat the reservoir rock, crude oil and water, so the water saturation of the reservoir may influence the distillation mechanism of steam [13]. This experiment is to determine the distillation rate of crude oil under different oil saturation in the reservoir. In addition to different oil saturation of the core in each experiment, other experimental conditions are the same.

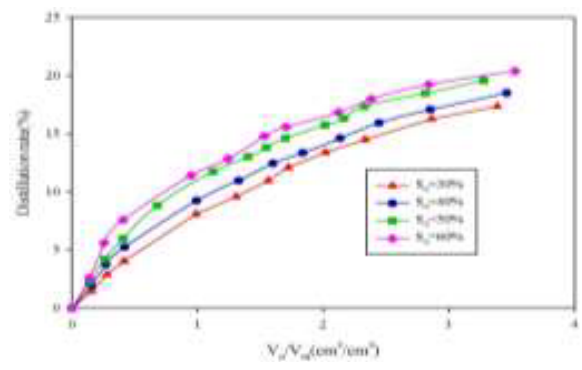

Fig. 3. The steam distillation rate of crude oil with different oil saturation ratios.

Figure 3 shows the steam distillation curve of the actual core (the permeability is $1.56 \mu \mathrm{m}^{2}$ ) with different saturation ratios when the crude oil is at $250^{\circ} \mathrm{C}$. The results indicate that with the increase of injected steam, the steam distillation rate of the crude oil continues to rise, when the volume of the accumulated steam water is 3.5 times of that of the original oil $\left(\mathrm{V}_{\mathrm{m}} / \mathrm{V}_{\mathrm{oi}}=3.5\right)$, the steam distillation rate of crude oil is up to about $20 \%$. The distillation rate of crude oil in 
the core increases with the rise of oil saturation, the reason is that high water content in the core inhibits the vaporization of the light components of crude oil. In the core with high oil content, the small moisture content is conductive to the vaporization of light components of crude oil.

\subsection{The influence of steam temperature on the steam distillation rate of crude oil}

One of the important mechanisms of steam injection production of heavy oil is the effect of viscosity reduction by heating. For this mechanism, the temperature of the injected steam does not accord with the rule-the higher, the better. Therefore, the injected steam should make the formation oil become Newtonian fluid to meet the Darcy flow condition [14]. For another important mechanism-the steam distillation, the higher temperature and dryness means better steam distillation effect.

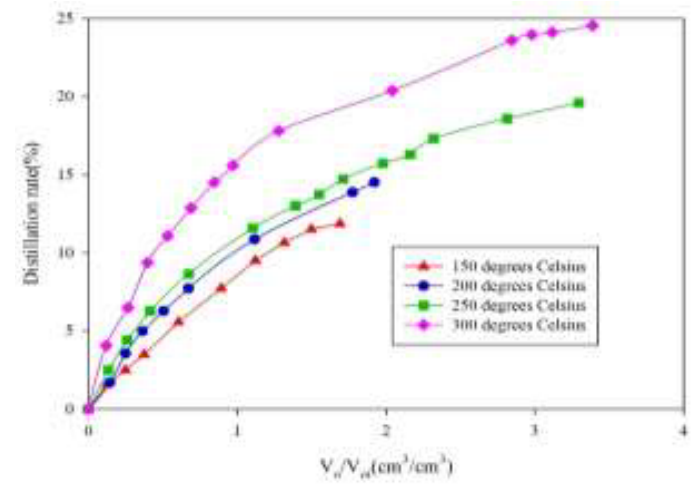

Fig. 4. The steam distillation rate of crude oil at different temperatures.

Figure 4 shows the steam distillation curves of crude oil in experimental core (the permeability is $1.56 \mu \mathrm{m}^{2}$ ) at different temperatures. It can be seen from the figure that under saturated conditions, when the temperature increases from $150{ }^{\circ} \mathrm{C}$ to $200{ }^{\circ} \mathrm{C}, 250{ }^{\circ} \mathrm{C}$ and $300{ }^{\circ} \mathrm{C}$, the steam distillation rate of crude oil respectively rises by $2.6 \%, 7.8 \%$ and $12.7 \%$. This indicates that the increase in steam temperature may gradually raise the distillation rate. For under saturated conditions, the rise in temperature may lead to the increase in enthalpy of wet saturated steam.

\subsection{The influence of system pressure on the steam distillation rate of crude oil}

The experiment to explore the influence of system pressure on the steam distillation rate of crude oil is to measure the changes of steam distillation rate under different system pressure when the steam is heated to $300{ }^{\circ} \mathrm{C}$. The saturated steam pressure is $8.583 \mathrm{MPa}$ when it is heated to $300{ }^{\circ} \mathrm{C}$, so the steam whose system pressure is less than $8.583 \mathrm{MPa}$ is called superheated system.

Figure 5 shows the curves of distillation characteristics of crude oil in the rock core when the pressure is respectively $1.0 \mathrm{MPa}, 2.0 \mathrm{MPa}, 4.0 \mathrm{MPa}, 6.0 \mathrm{MPa}$ and $8.55 \mathrm{MPa}$ at the temperature of $300{ }^{\circ} \mathrm{C}$. The experimental results indicate that at the same temperature of $300{ }^{\circ} \mathrm{C}$, the distillation rate of crude oil is respectively $39.4 \%, 36.8 \%, 32.4 \%$, $27.4 \%$ and $24.5 \%$. Compared with that under the saturated condition $(8.55 \mathrm{MPa})$, with the system pressure, the distillation rate respectively rises by $2.9 \%, 7.9 \%, 11.3 \%$ and $14.9 \%$. This is because at the same temperature, with the decrease in the system pressure, the wet saturated steam is gradually converted into superheated steam whose enthalpy value is greater than that of dry saturated steam (enthalpy with $100 \%$ dryness) and far outweighs that of the wet saturated steam. 


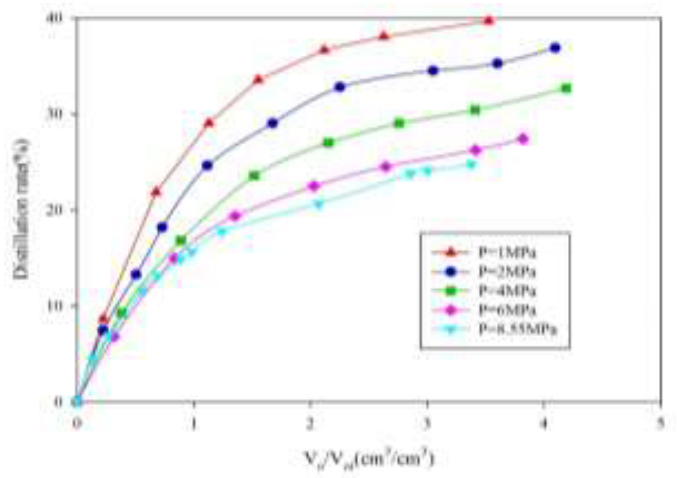

Fig. 5. The steam distillation rate of crude oil under different system pressure.

\subsection{The influence of injection rate on the steam distillation rate of crude oil}

In the actual operation process of the steam injection, there is an optimal steam injection rate. If conditions permit, the increase in injection rate is conducive to improving the steam dryness at the bottom and the effect of steam distillation [12]. However, with the same dryness, the influence of steam injection rate on the steam distillation rate of crude oil is not clear. This experiment is to measure the steam distillation rate of crude oil under different injection rates.

The experiment is carried out in the rock core with the temperature of $250{ }^{\circ} \mathrm{C}$, the system pressure of $3.95 \mathrm{MPa}$, and the permeability of $1.602 \mu \mathrm{m}^{2}$. In this experiment, four different injection rates are adopted, $2.0 \mathrm{ml} / \mathrm{min}, 5.0 \mathrm{ml} / \mathrm{min}$, $10.0 \mathrm{ml} / \mathrm{min}$, and $15.0 \mathrm{ml} / \mathrm{min}$, and the results are as shown in figure 6 . The maximum difference between distillation rates with these four injection rates is only $0.8 \%$, which means that the steam injection rate has little effect on the distillation rate of crude oil.

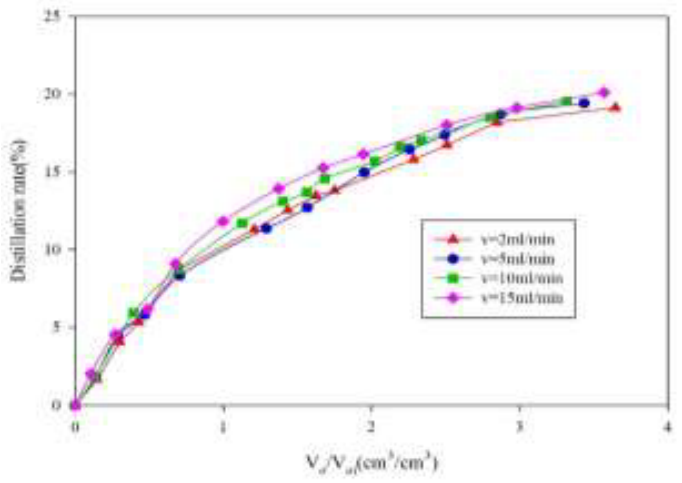

Figure 6. Steam distillation rates of crude oil with different steam injection rates.

\subsection{The influence of viscosity on the steam distillation rate of crude oil}

For the crude oil with different properties, the major difference is reflected in the viscosity [15]. This experiment is to explore the viscosity of representative heavy oil, aiming to analyze the relationship between the viscosity and steam distillation rate.

The experimental results are as shown in Figure 7. The steam distillation rate decreases with the increase of viscosity. For example, when the temperature is $250{ }^{\circ} \mathrm{C}$, the steam distillation rate of crude oil with small viscosity oil $(<2500 \mathrm{mPa} . \mathrm{s})$ is more than $10 \%$, while for the one with great viscosity $(>5000 \mathrm{mPa} . \mathrm{s})$, the distillation rate is less than $10 \%$. However, it is not reliable to find out how the distillation rate changes with the viscosity of crude oil because distillation rate is not only affected by viscosity, which is also related with other relative chemical properties of crude oil. 


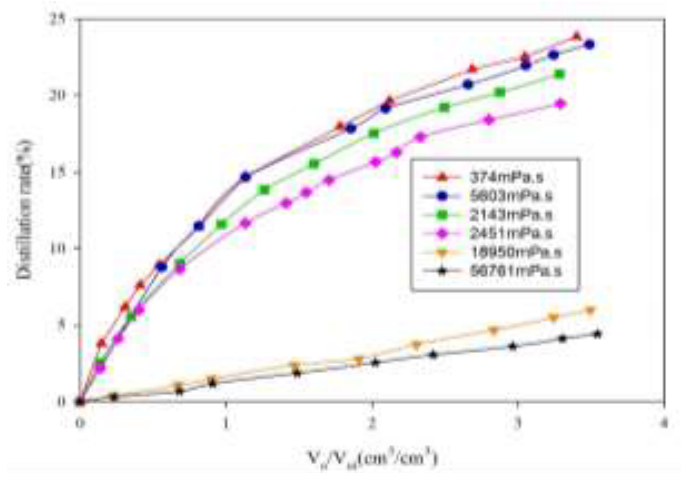

Fig. 7. The steam distillation rate of crude oil when the viscosities are different.

\section{Conclusion}

- The natures of crude oil are the inherent factors affecting its steam distillation, while temperature and pressure are the key external factors.

- Under the same conditions of steam injection, the distillation rate decreases with the increase of system pressure.

- Under the saturated condition, the steam distillation rate slightly increases with the rise of steam temperature. The superheated steam could greatly improve the steam distillation rate of crude oil, which is particularly evident for the heavy oil.

- The permeability, initial oil saturation and injection rate in the porous medium have subtle effects on the steam distillation rate. There is a slight increase in the steam distillation rate with the rise of the permeability and initial oil saturation, while the influence of the injection rate is almost negligible.

\section{References}

Online references will be linked to their original source, only if possible. To enable this linking extra care should be taken when preparing reference lists.

1. RICHARDSON W C, BELADI M K, WU C H. Steam Distillation Studies for the Kern River Field. SPE Reservoir Evaluation \& Engineering, 2000, 3(1): 13 - 22.

2. DUERKSEN J H, HSUEH L. Steam Distillation of Crude Oils. Society of Petroleum Engineers Journal, 1983, 23(2): $265-71$.

3. B.T.WILLMAN, V.V.VALLEROY, W.RUNBERG G, et al. Laboratory studies of oil recovery by steam injection. Journal of Petroleum Technology, 1961, 13(7): 681-90.

4. JOHNSON F S, WALKER E G, BAYAZEED A F. Oil vaporization during steamflooding . Journal of Petroleum Technology, 1971, 23(4): 731-42.

5. ALI S M F, K.D.KIMBER, V.R.PUTTAGUNTA. New Scaling Criteria And Their Relative Merits For Steam Recovery Experiments. Journal of Canadian Petroleum Technology, 1988, 27(4): 67-72.

6. K.C.HONG, J.W.AULT. Effects of Noncondensable Gas Injection on Oil Recovery by Steamflooding . Journal of Petroleum Technology, 1984, 36(12): 2160 - 70.

7. MURER A S, MCCLENNEN K L, LARSON D C, et al. Steam Injection Project in Heavy-Oil Diatomite . SPE Reservoir Evaluation \& Engineering, 2000, 3(1): 2-12.

8. BYCHKOV A, BOERRIGTER P M, HEEL A P V. Steam Injection Into Fractured Carbonates - The Physical Recovery Mechanisms Analyzed and Upscaled. Abu Dhabi International Petroleum Exhibition and Conference. Abu Dhabi, UAE. 2008.

9. RIVEROS G L V, BARRIOS H. Steam Injection Experiences in Heavy and Extra-Heavy Oil Fields, Venezuela . SPE Heavy Oil Conference and Exhibition. Kuwait City, Kuwait. 2011.

10. TANG G-Q, INOUYE A, LOWRY D, et al. Recovery Mechanism of Steam Injection in Heavy Oil Carbonate Reservoir. SPE Western North American Region Meeting. Anchorage, Alaska, USA. 2011.

11. DENNEY D. Steamflooding To Enhance Recovery of a Waterflooded Light-Oil Reservoir. Journal of Petroleum Technology, 2012, 64(1): 64-6.

12. A.SHAH A, P.FISHWICK R, A.LEEKE G, et al. Experimental Optimization of Catalytic Process In Situ for Heavy-Oil and Bitumen Upgrading. Journal of Canadian Petroleum Technology, 2011, 50(11-12): 33-47. 
13. DEHGHANI K, EHRLICH R. Evaluation of the Steam-Injection Process in Light-Oil Reservoirs. SPE Reservoir Evaluation \& Engineering, 2001, 4(5): 395 - 405.

14. A.MOLLAEI, B.MAINI. Steam Flooding of Naturally Fractured Reservoirs: Basic Concepts and Recovery Mechanisms. Society of Petroleum Engineers Journal, 2010, 49(1): 65 - 70.

15. A.YAZDANI, MAINI B B. Measurements and Modelling of Phase Behaviour and Viscosity of a Heavy Oil/Butane System . Journal of Canadian Petroleum Technology, 2010, 49(2): 9-14. 